Research Article

\title{
Use of Electrochemical Impedance Spectroscopy for the Evaluation of Performance of PEM Fuel Cells Based on Carbon Cloth Gas Diffusion Electrodes
}

\author{
Saverio Latorrata $(\mathbb{D}$, Renato Pelosato, Paola Gallo Stampino, Cinzia Cristiani, \\ and Giovanni Dotelli
}

\begin{abstract}
Department of Chemistry, Materials and Chemical Engineering “Giulio Natta”, Politecnico di Milano, Piazza Leonardo da Vinci 32, 20133 Milano, Italy
\end{abstract}

Correspondence should be addressed to Saverio Latorrata; saverio.latorrata@polimi.it

Received 15 November 2017; Accepted 13 February 2018; Published 28 March 2018

Academic Editor: Jau-Wern Chiou

Copyright (c) 2018 Saverio Latorrata et al. This is an open access article distributed under the Creative Commons Attribution License, which permits unrestricted use, distribution, and reproduction in any medium, provided the original work is properly cited.

\begin{abstract}
Polymer electrolyte membrane fuel cells (PEMFCs) have attracted great attention in the last two decades as valuable alternative energy generators because of their high efficiencies and low or null pollutant emissions. In the present work, two gas diffusion electrodes (GDEs) for PEMFCs were prepared by using an ink containing carbon-supported platinum in the catalytic phase which was sprayed onto a carbon cloth substrate. Two aerograph nozzles, with different sizes, were used. The prepared GDEs were assembled into a fuel cell lab prototype with commercial electrolyte and bipolar plates and tested alternately as anode and cathode. Polarization measurements and electrochemical impedance spectroscopy (EIS) were performed on the running hydrogen-fed PEMFC from open circuit voltage to high current density. Experimental impedance spectra were fitted with an equivalent circuit model by using ZView software which allowed to get crucial parameters for the evaluation of fuel cell performance, such as ohmic resistance, charge transfer, and mass transfer resistance, whose trends have been studied as a function of the applied current density.
\end{abstract}

\section{Introduction}

Polymer electrolyte membrane fuel cells (PEMFCs) are interesting alternative energy generators because of their high output power density and conversion efficiency, which are associated with modularity, low working temperature (less than $100^{\circ} \mathrm{C}$ ), and environmentally friendly emission. However, a commercial widespread of PEMFCs is still prevented by issues related to cost reduction, electrocatalyst activity, and material durability and stability [1-4].

The catalytic layer is the place where the redox reactions occur; thus, its structural and wetting properties are of paramount importance for the optimal operation of the fuel cell [5]. PEMFCs are usually platinum catalyzed, and the cost of the catalyst has therefore a great influence on the cost of these fuel cells. Thus, a massive use of FCs in the car industry entails finding a material alternative to a platinum catalyst. Many efforts have been done in this field $[6,7]$, but Pt-based catalysts still remain the state-of-the-art materials $[3,8,9]$.

In the design of an active catalyst, Pt dispersion must be considered [10] in addition to Pt loading to maximize the active surface area. Furthermore, ionomer content and distribution, microstructure, and porosity are essential factors in providing a fast proton transfer rate from the anode to the cathode; of course, this has to be attained without increasing the mass transfer resistance to obtain high efficiency in the electrochemical conversion.

In a PEMFC, the catalyst layer can be applied directly to the electrolytic membrane (catalyst-coated membrane (CCM)) or, alternatively, to the gas diffusion medium (GDM) $[11,12]$. In this latter case, the so-called gas diffusion electrode (GDE) is obtained, which is a multilayer structure with a quite complex composition. To prepare a GDE, the 
catalyst powder (i.e., Pt supported on C) is coated onto a gas diffusion medium (GDM). GDM usually consists of a sheet of macroporous carbon cloth or paper (usually called gas diffusion layer (GDL)) coated with a thin layer of carbon black and polytetrafluoroethylene, referred to as microporous layer (MPL). In the recent literature, the interest in the preparation of GDEs is increasing [13-18].

Catalytic layers are generally deposited onto the GDM by means of a variety of techniques, such as brush printing [19], ultrasonic spraying [13], and flexography printing [14] using an ink prepared by dispersing the $\mathrm{Pt} / \mathrm{C}$ catalyst in a mixture of solvents. A lot of variables have to be considered in the preparation of the catalytic ink, such as nature and ratios of the components or mixing technique and mixing time. All these factors contribute to define the appropriate rheological behavior and the stability of the ink [20] for the specific deposition technique.

The performance of fuel cells and influence of different components on it are usually assessed by polarization curves which are useful to know the trend of cell potential and of the output power density as a function of the current density. Therefore, such curves are related to the macroscopic behavior of the whole device and give no precise information about the effect of inner components. In order to overcome this issue, electrochemical impedance spectroscopy (EIS) has to be carried out together with polarization curve measurements. EIS is a well-established technique for a complete analysis of electrochemical device behavior, but it has also been used in other fields of applied sciences in order to evaluate, for instance, the corrosion behavior of stainless steel [21] and different metallic alloys [22, 23] at various operating conditions and in different media and even for biomedical applications [24].

Especially for fuel cell applications, EIS is a powerful tool which allows a deep in situ kinetic analysis of catalytic phenomena as well as the separation of different processes contributing to overpotential [25] depending on frequency domain. Indeed, by performing EIS measurements, overall ohmic resistance (often referred to as high-frequency resistance (HFR)) of the whole fuel cell device, charge transfer resistance related to activation polarization occurring on catalytic surface, and mass transfer resistance due to diffusive limitations arising at high current density can be obtained. Moreover, depending on the evaluation of different relaxation time and reaction rates, anodic and cathodic contributions to the electrochemical process can be separated [26]. It can be sometimes expansive and complex but the information content of EIS is much higher than DC techniques or single frequency measurements, and it can test component properties and durability within an assembled device, such as a fuel cell [26].

The aim of the present work is to investigate, by EIS and polarization curves, the effect on fuel cell performance of two different GDEs prepared via spray coating technology. It has to be intended as a methodological work to understand the potentiality and the benefit of employing EIS together with polarization curves in assessing cell component quality and behavior.

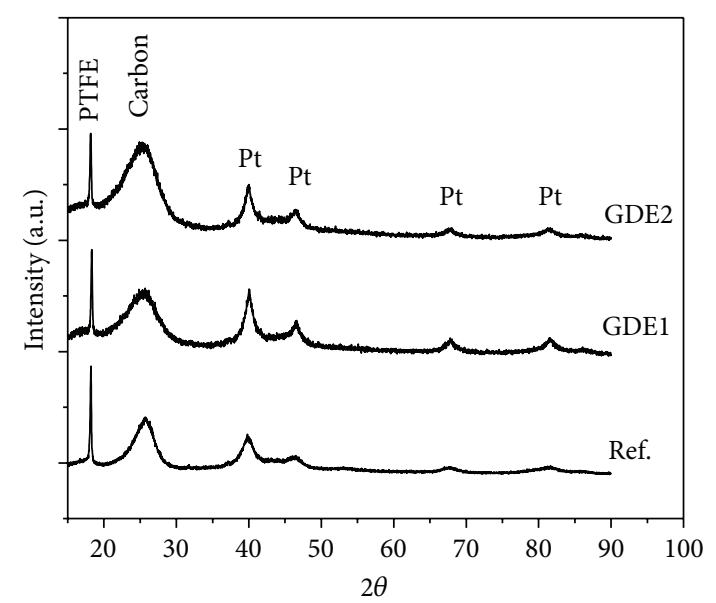

FIgURE 1: Comparison of the XRD spectra of GDE1, GDE2, and Ref.

The performances of the prepared GDEs, both at the anode and at the cathode side, were compared with those of a commercial GDE reference sample (E-TEK LT140) in a lab-scale single cell.

\section{Materials and Methods}

2.1. Sample Preparation. Commercial gas diffusion media (SCCG5-P10, SAATI) were used as substrates for the deposition of the catalytic layer. They consist of a carbon clothbased GDL coated with a carbon microporous layer (MPL) containing 12 wt $\%$ of PTFE [27].

A catalytic ink to be sprayed onto the GDM was prepared according to reference [28]. A commercial (E-TEK XC-72) $\mathrm{Pt} / \mathrm{C}$ catalytic powder was mixed with a $5 \mathrm{wt} \%$ Nafion ${ }^{\circledR}$ solution (Aldrich) and dispersed in a mixture of isopropanol and water upon stirring for $1 \mathrm{~h}$ and subsequently sonicated for $1.5 \mathrm{~h}$. Two gas diffusion electrodes (referred to as GDE1 and GDE2) were obtained by spraying the ink onto the substrate; an aerograph with nitrogen as gas carrier was employed, and a Pt loading of $0.5 \mathrm{mg} / \mathrm{cm}^{2}$ and $0.4 \mathrm{mg} / \mathrm{cm}^{2}$ for GDE1 and GDE2, respectively, was obtained. Two nozzles with different apertures (diameter higher than $1 \mathrm{~mm}$ and lower than $1 \mathrm{~mm}$ for GDE1 and GDE2, resp.) were used and the properties of the two obtained GDEs were compared with reference electrode (Ref.), E-TEK LT140 with a catalytic loading $(\mathrm{Pt} / \mathrm{C})$ of $0.5 \mathrm{mg} / \mathrm{cm}^{2}$.

After deposition, a thermal treatment in air at $70^{\circ} \mathrm{C}$ for 15 min was performed to strengthen and fix the catalytic layer to the support. For the cell testing, a commercial $50 \mu \mathrm{m}$ thick Nafion 212 membrane (a perfluorocarbonsulfonic acid ionomer, supplied by Sigma-Aldrich) was used as electrolyte.

2.2. Structural and Morphological Analysis. Phase compositions of the obtained GDEs were analyzed by XRD using a Bruker D8 Advance instrument. Spectra were recorded using the $\mathrm{CuK} \alpha$ radiation $(\lambda=1.54 \AA)$ in the $15-90^{\circ} 2 \theta$ range, with a step of $0.02^{\circ} 2 \theta$ and counting time of $12 \mathrm{~s}$ per step. Crystallite size of $\mathrm{Pt}$ catalysts were evaluated via the Scherrer equation using the integral breadth $\beta$ of Pt (111) (200) (220), and (002) reflections. The crystallite sizes calculated from 

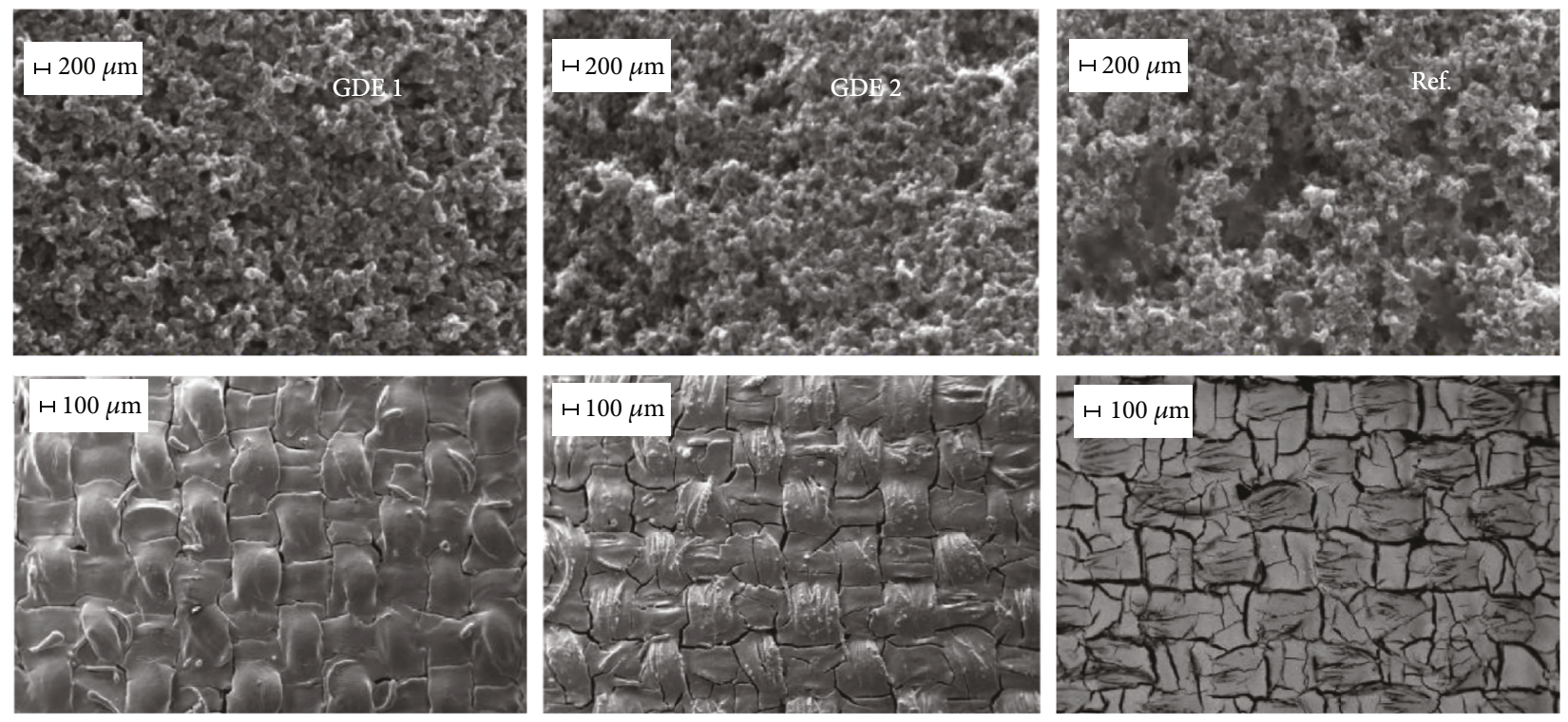

Figure 2: SEM micrographs of GDE1, GDE2, and Ref. at different magnifications.
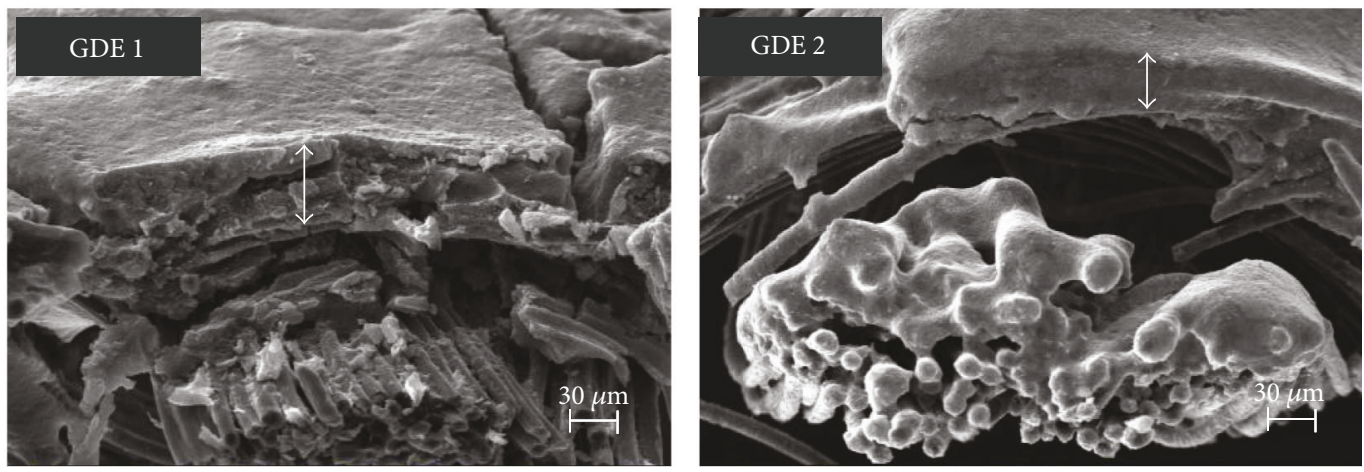

FIgURE 3: SEM images of the cross section of the coating layers of GDE1 and GDE2.

the single reflections have been averaged to obtain the reported values. For the sake of comparison, Ref. GDE was also characterized in the same way. Morphology observations of the GDEs were carried out with a Carl Zeiss EVO50VP scanning electron microscope (SEM) equipped with an energy dispersive spectrometer (EDS) for elemental analysis.

2.3. Electrochemical I-V Characterization. Electrochemical performances of GDE1 and GDE2 were tested in a single lab-scale cell (Fuel Cell Technologies) having a single serpentine plate at the anode and a triple parallel serpentine plate at the cathode side.

GDE1 was assembled alternately at the cathode and at the anode side producing such a MEA assembly: GDE1// Membrane//Ref.; the same setup was realized with GDE2 (GDE2//Membrane//Ref.). In the following, the two assemblies will be referred to as Assembly 1 and Assembly 2, respectively; for the sake of comparison, a third assembly with Ref. GDE at both electrodes was tested (Assembly Ref). When GDE1 works as an anode, the assembly will be labeled Assembly 1A; when GDE1 works as a cathode, it will be referred to as Assembly 1C; similarly for GDE2, the labels will be Assembly 2A and Assembly 2C. The active area was $25 \mathrm{~cm}^{2}$ for all the assemblies. Pure hydrogen and air were fed at the anode and cathode, respectively. Two flow rate regimes were tested: (1) $0.2 \mathrm{Nl} / \mathrm{min}$ of hydrogen and $1.0 \mathrm{Nl} / \mathrm{min}$ of air, corresponding to a stoichiometric ratio $S=1.2 / 2.4 \mathrm{~A} / \mathrm{C}$ at $1 \mathrm{~A} / \mathrm{cm}^{2}$ and (2) $0.5 \mathrm{Nl} / \mathrm{min}$ of hydrogen and $2.0 \mathrm{Nl} / \mathrm{min}$ of air, corresponding to a stoichiometric ratio $S=2.9 / 4.8 \mathrm{~A} / \mathrm{C}$ at $1 \mathrm{~A} / \mathrm{cm}^{2}$ and were controlled and detected by a calibrated flow meter. The degree of humidity and the gas temperature were controlled by saturators and temperature controllers, respectively: the temperature of the cell was kept at $60^{\circ} \mathrm{C}$ and the inlet gases were fully humidified (RH A/C 100/100). An electronic load (RBL488-50-150-800) connected to the cell measured and controlled the voltage, the current, and the generated electric power. Polarization curves were recorded under potentiostatic mode in the voltage range from OCV to $0.1 \mathrm{~V}$ with steps of $0.05 \mathrm{~V}$. At each step, the resulting current density was recorded (400 seconds per step, one point per second recorded). Current density values plotted in the steady-state polarization curves result from the averaging of the last 220 points recorded at each 

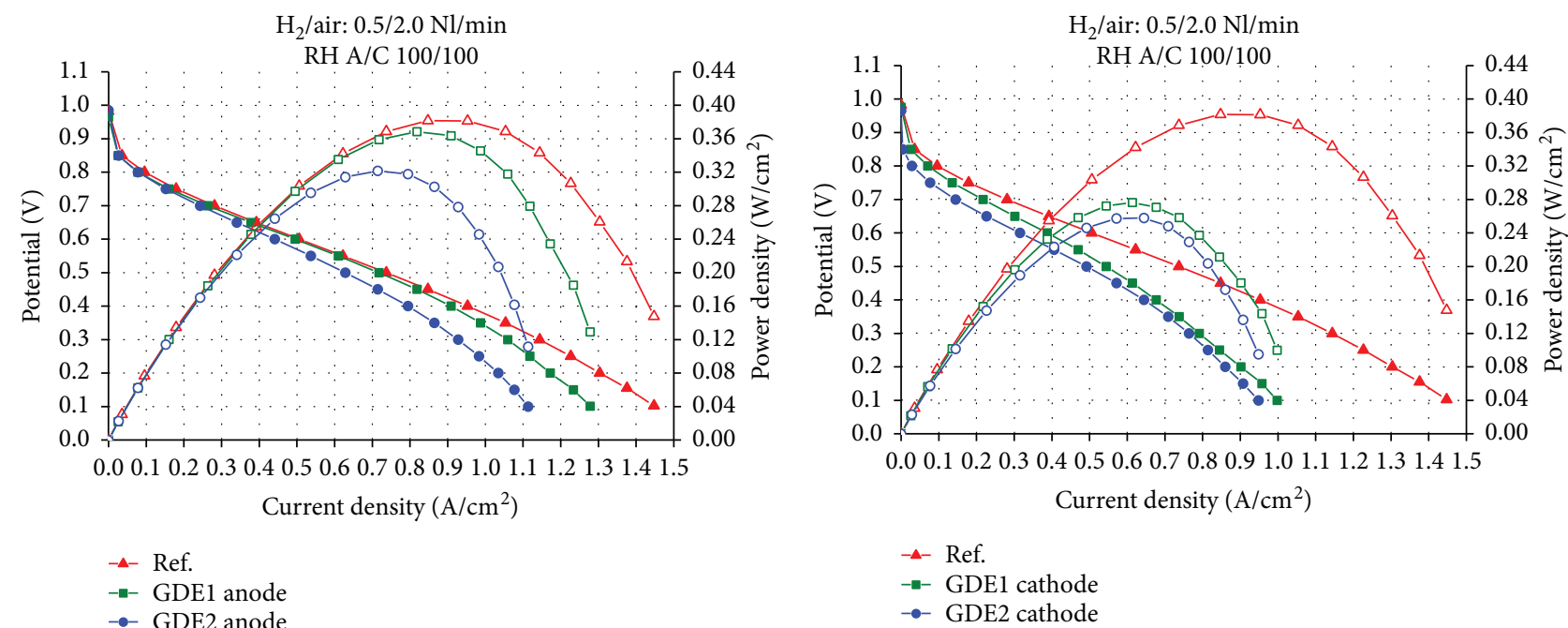

(a)

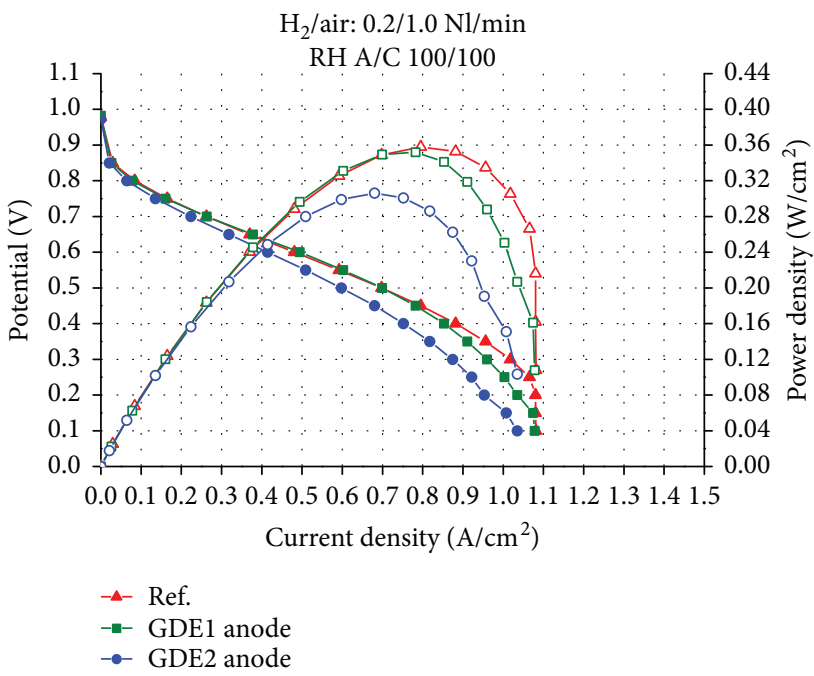

(b)

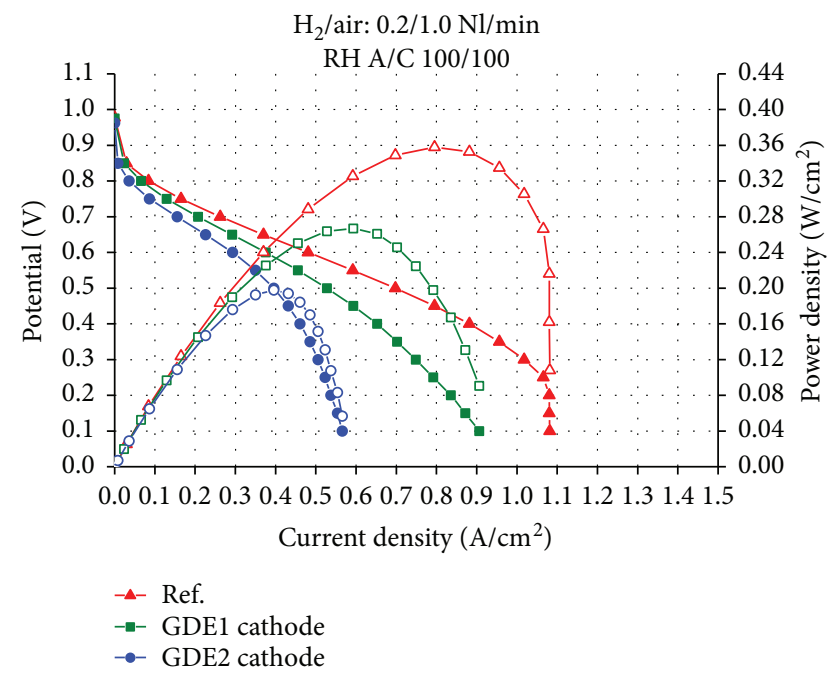

(c)

(d)

Figure 4: Polarization and power density curves at a high inlet gas flow rate $(\mathrm{a}, \mathrm{b})-0.5 / 2 \mathrm{Nl} / \mathrm{min}_{2} /$ air - and at a low inlet gas flow rate (c, d) $-0.2 / 1 \mathrm{Nl} / \mathrm{min} \mathrm{H}_{2} /$ air.

step in order to minimize experimental artifacts due to transient phenomena [29].

2.4. Electrochemical Impedance Spectroscopy. Electrochemical impedance spectroscopy (EIS) of the running FC was performed using a frequency response analyzer (FRA) Solartron 1260 , directly connected to the electronic load (RBL488-50150-800). EIS was performed in galvanostatic mode [30] using an AC signal of amplitude $200 \mathrm{~mA}[31,32]$. Impedance spectra were collected by sweeping frequencies over the range $0.5 \mathrm{~Hz}-1 \mathrm{kHz}$, acquiring ten points per decade. The EIS spectra were recorded at OCV and from low to high current density (up to $1 \mathrm{~A} / \mathrm{cm}^{2}$ ). Five full spectra for each current density value were acquired, and the impedance spectrum finally used in the discussion was the result of an averaging procedure. The experimental spectra were modeled with equivalent circuits by employing the $\mathrm{ZView}^{\circledR}$ software (Scribner Associates). The equivalent circuit used $[33,34]$ is made of a resistance $\left(R_{\mathrm{s}}\right)$ in series with two parallel constant phase elements $(\mathrm{CPE}) /$ resistance circuits. $R_{\mathrm{s}}$ represents the ohmic losses, while the first $\mathrm{CPE}_{\mathrm{p}} / R_{\mathrm{p}}$ circuit models the activation polarization (i.e., charge transfer resistance) and the second one $\left(\mathrm{CPE}_{\mathrm{d}} / R_{\mathrm{d}}\right)$ is related to concentration losses due to mass transfer resistances. CPEs were used instead of pure capacitances to account for the capacitive losses that generally occur in porous electrodes [35].

\section{Results}

3.1. Microstructure and Morphology. In Figure 1, the XRD spectra of GDE1, GDE2, and Ref. are compared. The phase compositions of GDE1, GDE2, and Ref. samples are very similar and consist of a homogeneous mixture of amorphous carbon (JC-PDS 01-075-0444), crystalline PTFE, and crystalline Pt (JC-PDS 00-004-0802). Regardless of the nozzle aperture, the average $\mathrm{Pt}$ crystallite size is almost the same 


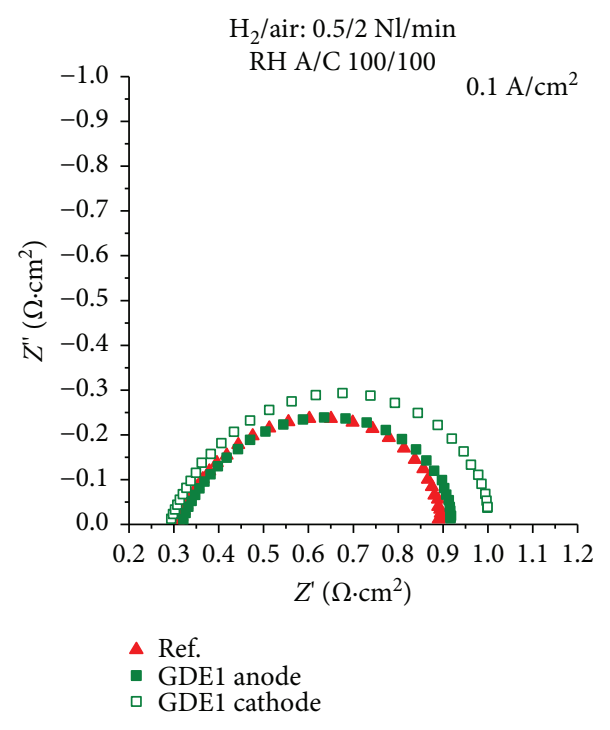

(a)

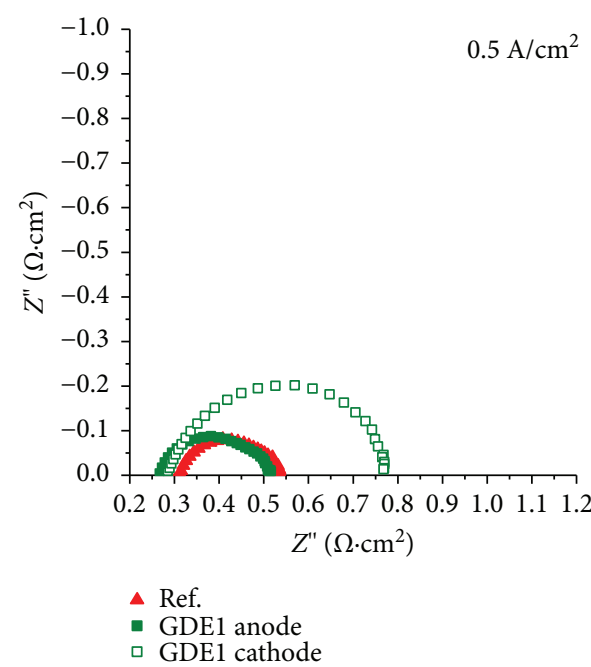

(c)

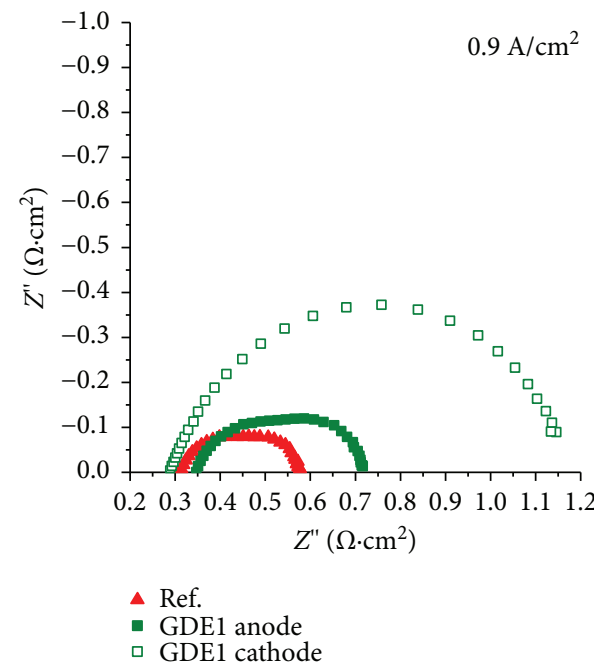

(e)

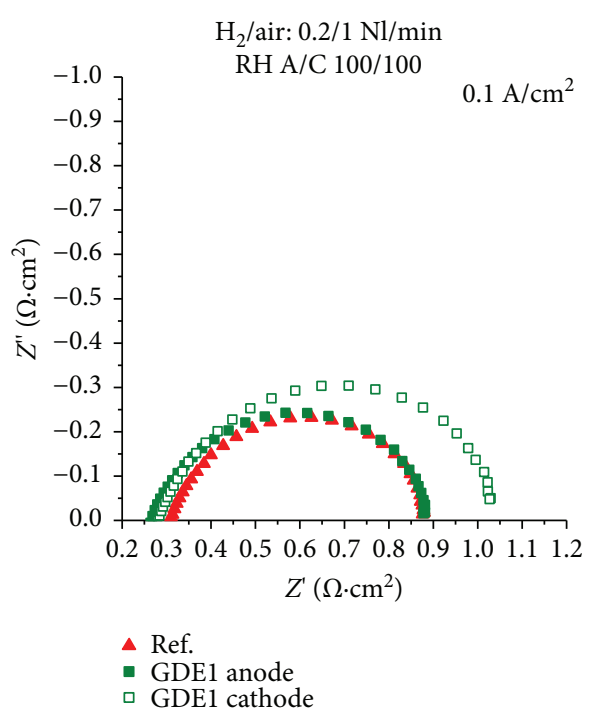

(b)

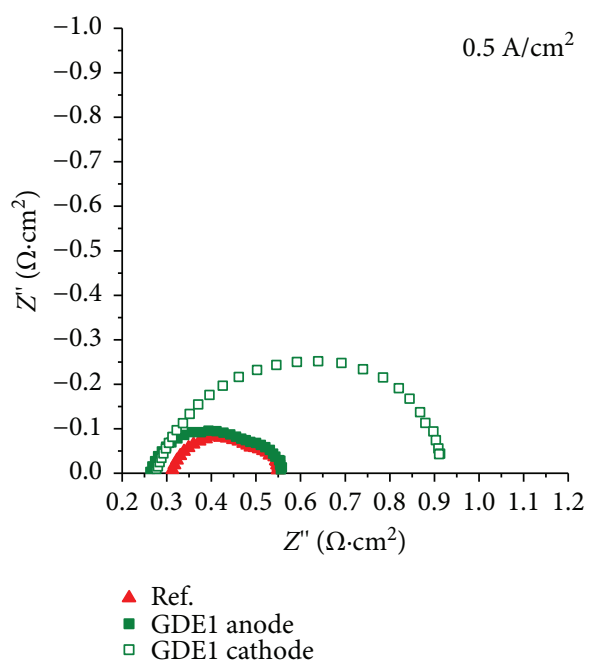

(d)

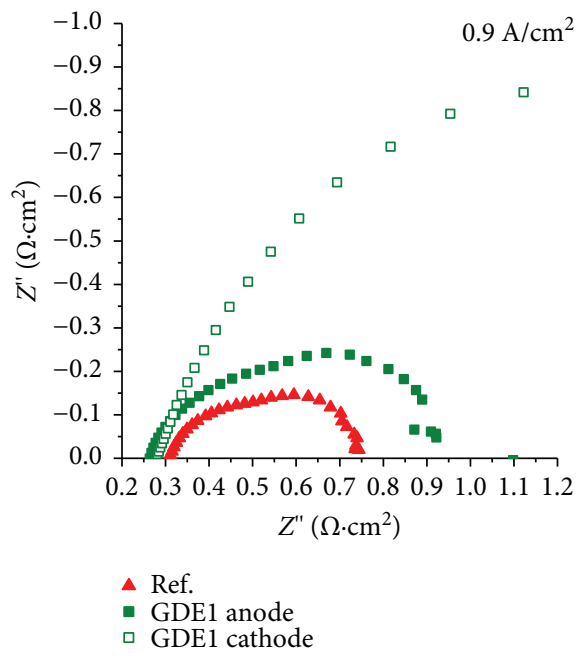

(f)

Figure 5: Example of impedance spectra acquired at different current densities (i.e., from $0.1 \mathrm{~A} / \mathrm{cm}^{2}$ to $\left.0.9 \mathrm{~A} / \mathrm{cm}^{2}\right)$ at high $(\mathrm{a}, \mathrm{c}, \mathrm{e})$ and low (b, d, f) inlet gas flow rate for the reference sample, GDE1 anode, and GDE1 cathode. 


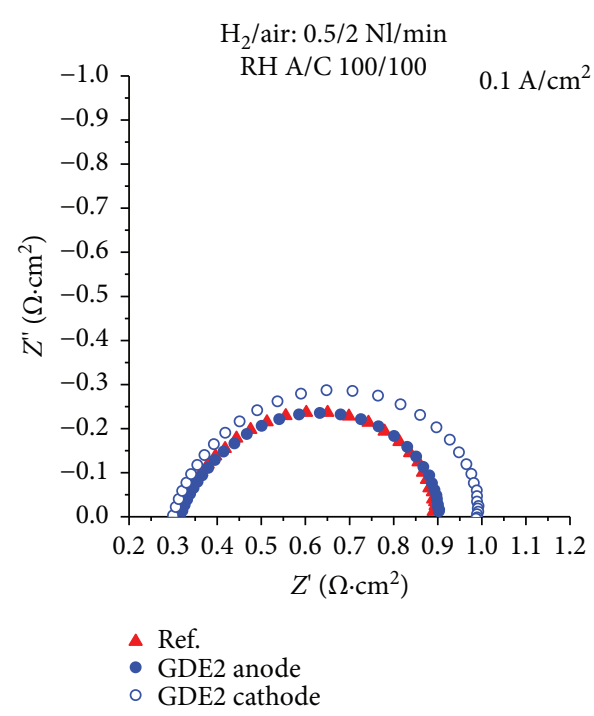

(a)

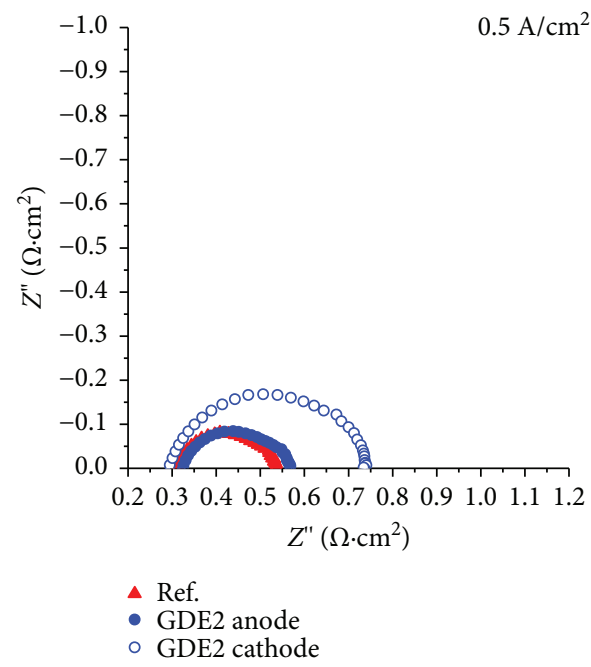

(c)

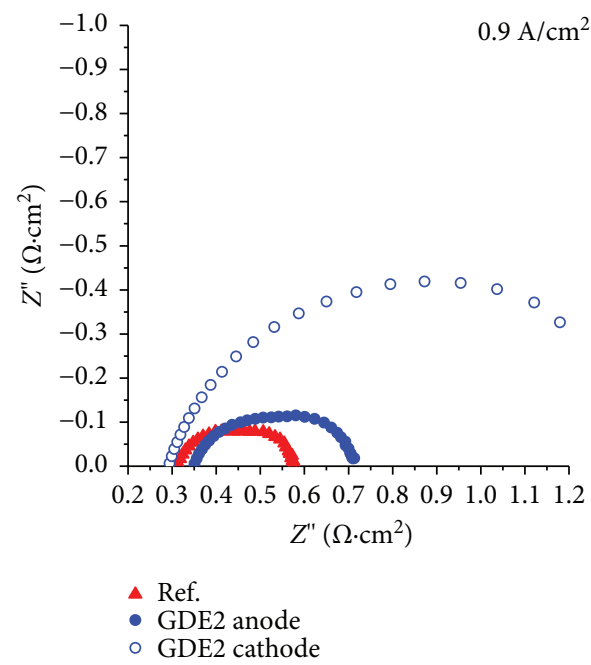

(e)

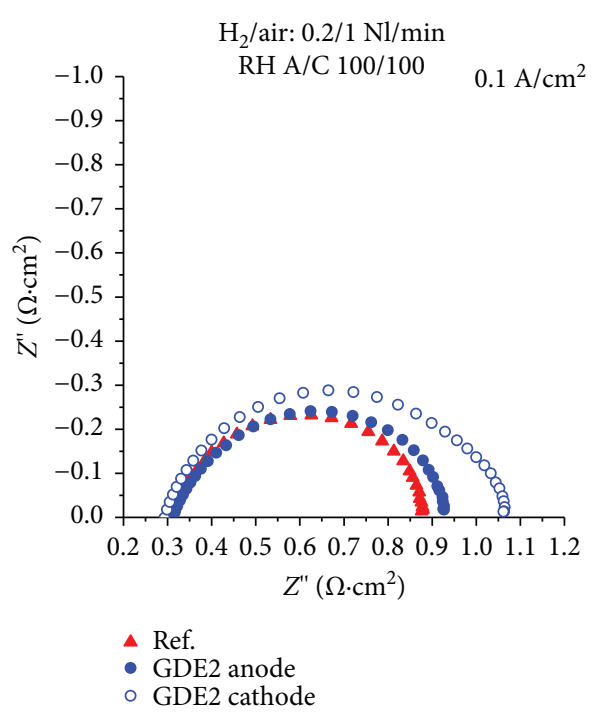

(b)

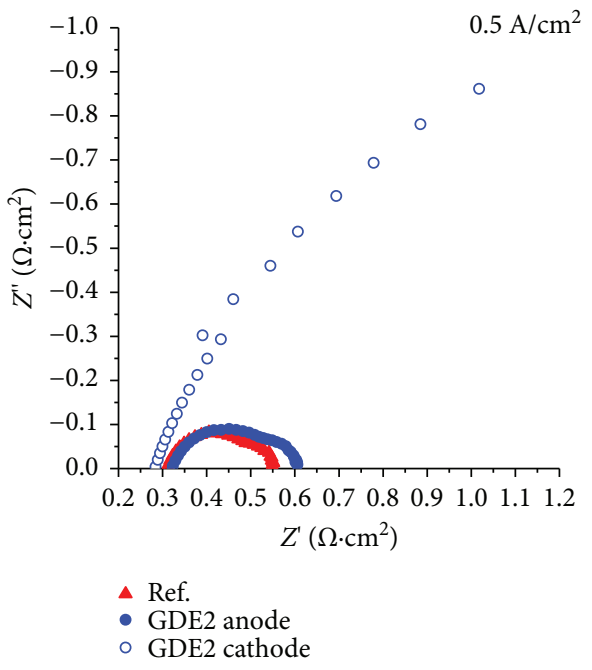

(d)

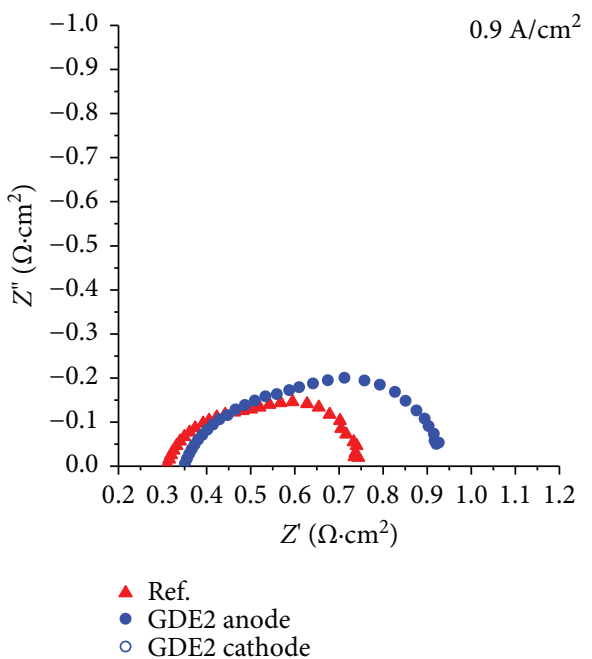

(f)

Figure 6: Example of impedance spectra acquired at different current densities (i.e., from $0.1 \mathrm{~A} / \mathrm{cm}^{2}$ to $0.9 \mathrm{~A} / \mathrm{cm}^{2}$ ) at high (a, c, e) and low $(b, d, f)$ inlet gas flow rates for the reference sample, GDE2 anode, and GDE2 cathode. 


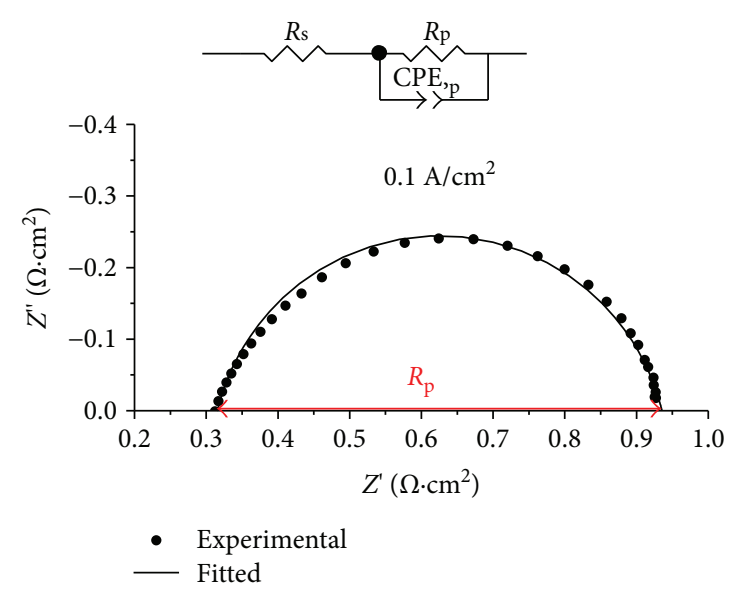

(a)

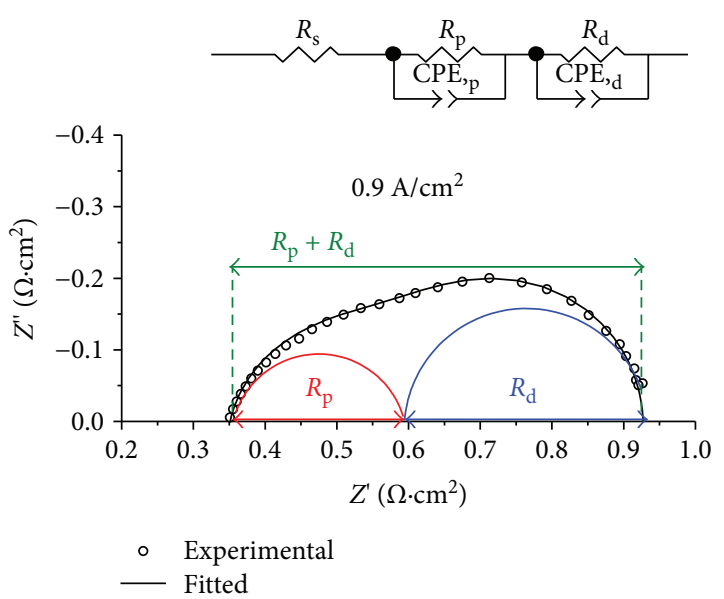

(b)

FIgURE 7: An example of modeling: equivalent circuits at low current density (a) and at high current density (b) for two spectra obtained for sample GDE2 anode at low inlet gas flow rate. $R_{\mathrm{p}}(\mathrm{a})$ and $R_{\mathrm{p}}+R_{\mathrm{d}}(\mathrm{b})$ are highlighted in order to clarify how the general output of the adopted procedure was obtained.

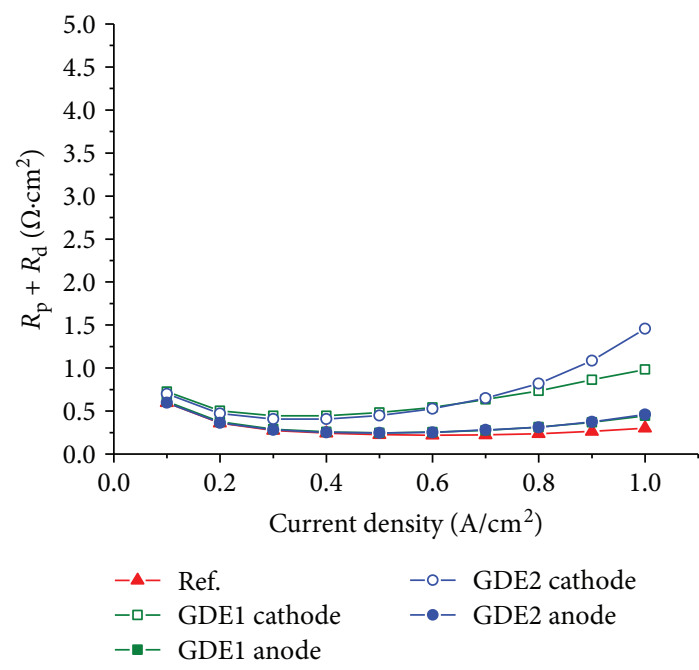

(a)

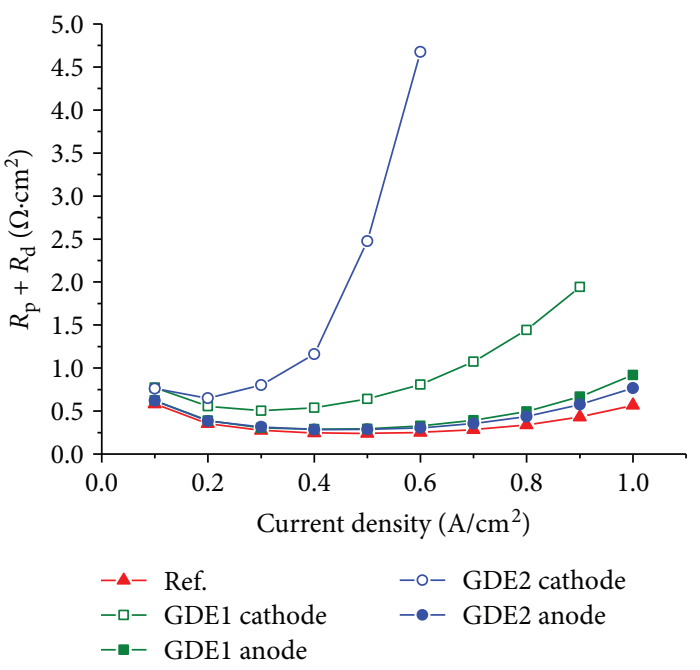

(b)

Figure 8: Sum of the charge transfer $\left(R_{\mathrm{p}}\right)$ and the mass transfer resistances $\left(R_{\mathrm{d}}\right)$ at a high inlet gas flow rate $(\mathrm{a})-0.5 / 2 \mathrm{Nl} / \mathrm{min} \mathrm{H}_{2} / \mathrm{air}-\mathrm{and}$ at a low inlet gas flow rate (b) $-0.2 / 1 \mathrm{Nl} / \mathrm{min}_{2}$ /air.

for the GDE1 and GDE2 samples: $d(\mathrm{GDE} 1)=7 \mathrm{~nm}$ and $d(\mathrm{GDE} 2)=6 \mathrm{~nm}$. Moreover, they are comparable with the crystallite size of Pt in Ref. sample, evaluated in the same way: $d$ (Ref.) $=5 \mathrm{~nm}$. This value fairly agrees with the catalyst producer data $(4 \mathrm{~nm})$. As this size is reported to be appropriate for PEMFCs applications [36], both the ink preparation procedure and the adopted deposition technique allow for the attainment of GDEs with properties comparable to those of the commercial sample (Ref.).

A similar micromorphology was observed for the three GDEs: a fluffy-like powder is present in each sample (Figure 2) suggesting that the use of nozzles of different dimensions does not affect the compactness of the powders in the carbon layer. However, small differences can be observed on the covering degree of the GDL. Indeed, the
Ref. surface is very smooth and no feature of the original warp and weft of the backing GDL is perceived. On the contrary, the feature of the GDL substrate is clearly evident in GDE1 and it is even more noticeable in GDE2. Nevertheless, the surfaces of GDE1 and GDE2 are more homogeneous than that of the Ref. sample that shows many cracks on the top layer. Accordingly, different thicknesses of the coating layers of the GDEs can be hypothesized: GDE1 and GDE2 coatings are probably thinner than the one of Ref.; indeed, thicker layers suffer larger mechanical stress during thermal treatment, producing a more cracked surface. Furthermore, GDE2 coating layer seems to be thinner than GDE1 even if both GDEs were obtained using the same ink formulation. Such a difference could be ascribed to different shear effects when nozzles of different apertures are used for the spray 
TABLE 1: The fitting parameters for the impedance spectra at different current densities (i.e., from OCV to $0.9 \mathrm{~A} / \mathrm{cm}^{2}$ ) and high inlet gas flow rate $\left(\mathrm{H}_{2} /\right.$ air: $\left.0.5 / 2 \mathrm{Nl} / \mathrm{min}\right)$.

\begin{tabular}{|c|c|c|c|c|c|c|c|c|}
\hline & Current density & Sample & $\mathrm{OCV}$ & $0.1\left(\mathrm{~A} / \mathrm{cm}^{2}\right)$ & $0.3\left(\mathrm{~A} / \mathrm{cm}^{2}\right)$ & $0.5\left(\mathrm{~A} / \mathrm{cm}^{2}\right)$ & $0.7\left(\mathrm{~A} / \mathrm{cm}^{2}\right)$ & $0.9\left(\mathrm{~A} / \mathrm{cm}^{2}\right)$ \\
\hline \multirow{6}{*}{ Ohmic resistance } & \multirow{5}{*}{$R_{\mathrm{s}}\left(\Omega \cdot \mathrm{cm}^{2}\right)$} & Reference & 0.317 & 0.315 & 0.313 & 0.311 & 0.311 & 0.311 \\
\hline & & GDE1 cathode & 0.291 & 0.291 & 0.286 & 0.285 & 0.285 & 0.286 \\
\hline & & GDE1 anode & 0.275 & 0.268 & 0.268 & 0.268 & 0.268 & 0.268 \\
\hline & & GDE2 cathode & 0.305 & 0.300 & 0.298 & 0.294 & 0.292 & 0.292 \\
\hline & & GDE2 anode & 0.321 & 0.321 & 0.321 & 0.322 & 0.326 & 0.339 \\
\hline & \multirow{5}{*}{$R_{\mathrm{p}}\left(\Omega \cdot \mathrm{cm}^{2}\right)$} & Reference & 6.350 & 0.596 & 0.276 & 0.199 & 0.176 & 0.174 \\
\hline \multirow{23}{*}{ Charge transfer circuit } & & GDE1 cathode & 5.598 & 0.727 & 0.236 & 0.208 & 0.241 & 0.109 \\
\hline & & GDE1 anode & 6.685 & 0.612 & 0.278 & 0.217 & 0.211 & 0.232 \\
\hline & & GDE2 cathode & 6.260 & 0.700 & 0.408 & 0.372 & 0.421 & 0.303 \\
\hline & & GDE2 anode & 6.369 & 0.596 & 0.280 & 0.209 & 0.222 & 0.276 \\
\hline & \multirow{5}{*}{$\mathrm{CPE}_{\mathrm{p}}-\mathrm{Q}\left(\mathrm{F} / \mathrm{cm}^{2}\right)$} & Reference & 0.047 & 0.035 & 0.038 & 0.041 & 0.047 & 0.048 \\
\hline & & GDE1 cathode & 0.059 & 0.044 & 0.054 & 0.065 & 0.097 & 0.129 \\
\hline & & GDE1 anode & 0.042 & 0.031 & 0.033 & 0.035 & 0.039 & 0.041 \\
\hline & & GDE2 cathode & 0.021 & 0.014 & 0.019 & 0.020 & 0.027 & 0.032 \\
\hline & & GDE2 anode & 0.043 & 0.032 & 0.034 & 0.034 & 0.047 & 0.067 \\
\hline & \multirow{5}{*}{$\mathrm{CPE}_{\mathrm{p}}-\mathrm{n}$} & Reference & 0.800 & 0.850 & 0.850 & 0.850 & 0.850 & 0.850 \\
\hline & & GDE1 cathode & 0.800 & 0.860 & 0.880 & 0.870 & 0.830 & 0.850 \\
\hline & & GDE1 anode & 0.800 & 0.850 & 0.850 & 0.850 & 0.850 & 0.850 \\
\hline & & GDE2 cathode & 0.800 & 0.880 & 0.860 & 0.880 & 0.860 & 0.880 \\
\hline & & GDE2 anode & 0.800 & 0.850 & 0.850 & 0.850 & 0.800 & 0.750 \\
\hline & \multirow{5}{*}{$C_{\mathrm{p}}\left(\mathrm{F} / \mathrm{cm}^{2}\right)$} & Reference & 0.035 & 0.018 & 0.017 & 0.0175 & 0.019 & 0.021 \\
\hline & & GDE1 cathode & 0.045 & 0.025 & 0.029 & 0.034 & 0.045 & 0.061 \\
\hline & & GDE1 anode & 0.031 & 0.015 & 0.014 & 0.015 & 0.016 & 0.018 \\
\hline & & GDE2 cathode & 0.013 & 0.007 & 0.008 & 0.010 & 0.013 & 0.017 \\
\hline & & GDE2 anode & 0.031 & 0.016 & 0.015 & 0.015 & 0.015 & 0.018 \\
\hline & \multirow{5}{*}{$f_{\mathrm{p}}(\mathrm{Hz})$} & Reference & 0.725 & 15.051 & 33.933 & 45.620 & 47.463 & 43.710 \\
\hline & & GDE1 cathode & 0.625 & 8.712 & 25.500 & 22.299 & 14.717 & 24.168 \\
\hline & & GDE1 anode & 0.768 & 17.110 & 40.159 & 48.738 & 46.540 & 38.558 \\
\hline & & GDE2 cathode & 1.959 & 30.661 & 45.629 & 41.178 & 29.298 & 30.677 \\
\hline \multirow{16}{*}{ Mass transfer circuit } & & GDE2 anode & 0.794 & 17.003 & 37.457 & 52.700 & 47.867 & 32.829 \\
\hline & \multirow{10}{*}{$\mathrm{CPE}_{\mathrm{d}}-\mathrm{Q}\left(\mathrm{F} / \mathrm{cm}^{2}\right)$} & Reference & - & - & - & 0.027 & 0.047 & 0.089 \\
\hline & & GDE1 cathode & - & - & 0.233 & 0.274 & 0.394 & 0.755 \\
\hline & & GDE1 anode & - & - & 0.012 & 0.028 & 0.064 & 0.137 \\
\hline & & GDE2 cathode & - & - & - & 0.075 & 0.228 & 0.782 \\
\hline & & GDE2 anode & - & - & - & 0.036 & 0.059 & 0.100 \\
\hline & & Reference & - & - & - & 1.516 & 0.579 & 0.281 \\
\hline & & GDE1 cathode & - & - & 0.068 & 0.065 & 0.063 & 0.051 \\
\hline & & GDE1 anode & - & - & 1.959 & 0.985 & 0.390 & 0.184 \\
\hline & & GDE2 cathode & - & - & - & 0.341 & 0.095 & 0.036 \\
\hline & & GDE2 anode & - & - & - & 0.741 & 0.447 & 0.262 \\
\hline & \multirow{5}{*}{$\mathrm{CPE}_{\mathrm{d}}-\mathrm{n}$} & Reference & - & - & - & 0.900 & 1.000 & 1.000 \\
\hline & & GDE1 cathode & - & - & 1.000 & 1.000 & 1.000 & 0.950 \\
\hline & & GDE1 anode & - & - & 1.000 & 1.000 & 1.000 & 1.000 \\
\hline & & GDE2 cathode & - & - & - & 0.850 & 0.940 & 0.910 \\
\hline & & GDE2 anode & - & - & - & 1.000 & 1.000 & 1.000 \\
\hline
\end{tabular}


TABLE 1: Continued.

\begin{tabular}{|c|c|c|c|c|c|c|c|}
\hline Current density & Sample & OCV & $0.1\left(\mathrm{~A} / \mathrm{cm}^{2}\right)$ & $0.3\left(\mathrm{~A} / \mathrm{cm}^{2}\right)$ & $0.5\left(\mathrm{~A} / \mathrm{cm}^{2}\right)$ & $0.7\left(\mathrm{~A} / \mathrm{cm}^{2}\right)$ & $0.9\left(\mathrm{~A} / \mathrm{cm}^{2}\right)$ \\
\hline \multirow{5}{*}{$C_{\mathrm{d}}\left(\mathrm{F} / \mathrm{cm}^{2}\right)$} & Reference & - & - & - & 1.065 & 0.579 & 0.281 \\
\hline & GDE1 cathode & - & - & 0.068 & 0.065 & 0.063 & 0.043 \\
\hline & GDE1 anode & - & - & 1.959 & 0.985 & 0.390 & 0.184 \\
\hline & GDE2 cathode & - & - & - & 0.179 & 0.074 & 0.025 \\
\hline & GDE2 anode & - & - & - & 0.741 & 0.447 & 0.262 \\
\hline \multirow{5}{*}{$f_{\mathrm{d}}(\mathrm{Hz})$} & Reference & - & - & - & 5.435 & 5.851 & 6.331 \\
\hline & GDE1 cathode & - & - & 10.082 & 8.924 & 6.361 & 4.867 \\
\hline & GDE1 anode & - & - & 6.962 & 5.774 & 6.390 & 6.282 \\
\hline & GDE2 cathode & - & - & - & 11.876 & 9.452 & 8.045 \\
\hline & GDE2 anode & - & - & - & 6.014 & 6.069 & 6.096 \\
\hline
\end{tabular}

procedure. A more narrow nozzle hole could result in higher shear effects that could produce a partial separation of the solid from the liquid in the ink during spraying. Such a modification will result in a lower solid load of the sprayed ink and therefore in a thinner coating layer in GDE2.

A direct measurement of the coating thickness has been attempted by SEM analysis of a sample cross section (Figure 3). A slightly higher thickness was found for GDE1 (about $40 \mu \mathrm{m})$ compared to GDE2 $(<30 \mu \mathrm{m})$, in agreement with the observed coverage of the cloths.

3.2. I-V Characterization. In Figure 4, the polarization curves of the FC incorporating one of the prepared GDEs at the anode or cathode are compared with the reference assembly with Ref. GDEs at both electrodes.

The best electrochemical performances of GDE1 and GDE2 are achieved when working as anodes, while poor results are obtained if they are used as cathodes. Assembly 1 is always superior to Assembly 2 in any operating condition. Low flow rates drastically reduce the cell performances in any assembly here tested, but the effect is noticeably less marked in Assembly 1 (see Figures 4(a) versus 4(c) and Figures 4(b) versus 4(d)). Moreover, Assembly 1A's performance compares very well with that of Assembly Ref up to about $0.8 \mathrm{~A} / \mathrm{cm}^{2}$ (Figures $4(\mathrm{a})$ and $4(\mathrm{c})$ ).

3.3. Electrochemical Impedance Spectroscopy. In Figure 5, some representative impedance spectra of Assembly 1A and $1 \mathrm{C}$ are compared with those of Assembly Ref, at increasing current density (CD), for the two flow rate regimes (high and low); analogously, impedance spectra of Assembly $2 \mathrm{~A}$ and $2 \mathrm{C}$, obtained at the same selected current densities, are shown in Figure 6.

The impedance spectra were modeled with $\left[_{\text {parallel }} R\right.$ $\mathrm{CPE}]_{\mathrm{p}}-R_{\mathrm{s}}$ (low CD) and $\left[_{\text {parallel }} R-\mathrm{CPE}\right]_{\mathrm{p}}-R_{\mathrm{s}}-\left[_{\text {parallel }} R-\mathrm{CPE}\right]_{\mathrm{d}}$ (high CD) equivalent circuits to evaluate activation $\left(R_{\mathrm{p}}\right)$, diffusion $\left(R_{\mathrm{d}}\right)$, and ohmic $\left(R_{\mathrm{s}}\right)$ resistances [37]. In the low CD range, mass transfer limitations are negligible and for this reason there is no need of using two R/CPE parallel circuits to fit experimental spectra [34]. As an example, experimental and fitted impedance spectra of the running cell at low and high $\mathrm{CD}$ are shown in Figure 7, where the equivalent circuits used for the fitting are reported in the insets.
The worst performances of Assembly 1 (Figure 5) and Assembly 2 (Figure 6) primarily depend on the total internal resistance, namely, the sum of the two polarizations $R_{\mathrm{p}}+R_{\mathrm{d}}$; such sum is represented by the difference between right and left intercepts of the impedance spectrum with the real axis and reported in Figure 8 for tested samples.

In accordance with polarization curves, in any condition, $R_{\mathrm{p}}+R_{\mathrm{d}}$ increases upon increasing CD from 0.5 to $1.0 \mathrm{~A} / \mathrm{cm}^{2}$. Indeed, the total polarization resistance decreases somewhat from 0.1 to $0.3 \mathrm{~A} / \mathrm{cm}^{2}$ and this is usually ascribed to the lowering of the anode charge transfer resistance $[37,38]$; as such, this phenomenon occurs in all the assemblies, reference included. The increase in total polarization resistance is clear when GDE1/GDE2 works as an anode, but it becomes dramatic when operating as a cathode, which explains the poor performances of Assembly 1 and 2 compared to Ref. in the high $C D$ range.

On the contrary, the ohmic resistance $R_{\mathrm{s}}$ (Tables 1 and 2), that is, the high frequency intercept of the impedance spectrum, is comparable with the one of the reference assembly, or even lower; in any case, it is in the order of $0.3 \Omega \cdot \mathrm{cm}^{2}$ and does not vary appreciably upon increasing CD. The ohmic resistance $R_{\mathrm{s}}$ represents bulk material resistances and contact resistances [39], and among these, the highest is usually the membrane resistance. This, in turn, mainly depends on the internal humidity degree of the membrane itself; because the inlet gases were fully humidified, there is no reason for the ohmic resistance to vary with $\mathrm{CD}$, and indeed it does not.

Using the fitting results reported in Table 1 (low flow rate) and Table 2 (high flow rate), the characteristic capacitance $\left(C_{\mathrm{p}}\right.$ or $\left.C_{\mathrm{d}}\right)$ and the relaxation frequency $\left(f_{\mathrm{p}}\right.$ or $\left.f_{\mathrm{d}}\right)$, which are useful parameters in identifying the polarization subprocesses, were calculated based on the following equations [40]:

$$
\begin{gathered}
C_{i}=\frac{\left(R_{i} Q_{i}\right)^{1 / n_{i}}}{R_{i}}, \\
f_{i}=\frac{\left(R_{i} Q_{i}\right)^{-1 / n_{i}}}{2 \pi}, \\
\frac{1}{Z}=Y=Q(j w)^{n} .
\end{gathered}
$$


TABLE 2: The fitting parameters for the impedance spectra at different current densities (i.e., from OCV to $0.9 \mathrm{~A} \cdot \mathrm{cm}^{-2}$ ) and low inlet gas flow rates $\left(\mathrm{H}_{2} /\right.$ air: $\left.0.2 / 1 \mathrm{Nl} / \mathrm{min}\right)$.

\begin{tabular}{|c|c|c|c|c|c|c|c|c|}
\hline & Current density & Sample & OCV & $0.1\left(\mathrm{~A} / \mathrm{cm}^{2}\right)$ & $0.3\left(\mathrm{~A} / \mathrm{cm}^{2}\right)$ & $0.5\left(\mathrm{~A} / \mathrm{cm}^{2}\right)$ & $0.7\left(\mathrm{~A} / \mathrm{cm}^{2}\right)$ & $0.9\left(\mathrm{~A} / \mathrm{cm}^{2}\right)$ \\
\hline \multirow{6}{*}{ Ohmic resistance } & \multirow{5}{*}{$R_{\mathrm{s}}\left(\Omega \cdot \mathrm{cm}^{2}\right)$} & Reference & 0.312 & 0.312 & 0.312 & 0.313 & 0.313 & 0.313 \\
\hline & & GDE1 cathode & 0.285 & 0.285 & 0.285 & 0.276 & 0.276 & 0.276 \\
\hline & & GDE1 anode & 0.267 & 0.267 & 0.267 & 0.264 & 0.264 & 0.264 \\
\hline & & GDE2 cathode & 0.297 & 0.297 & 0.290 & 0.290 & - & - \\
\hline & & GDE2 anode & 0.316 & 0.316 & 0.311 & 0.319 & 0.333 & 0.351 \\
\hline & \multirow{5}{*}{$R_{\mathrm{p}}\left(\Omega \cdot \mathrm{cm}^{2}\right)$} & Reference & 5.789 & 0.583 & 0.274 & 0.198 & 0.194 & 0.220 \\
\hline \multirow{23}{*}{ Charge transfer circuit } & & GDE1 cathode & 5.669 & 0.771 & 0.505 & 0.361 & 0.289 & 0.261 \\
\hline & & GDE1 anode & 6.271 & 0.625 & 0.305 & 0.233 & 0.251 & 0.299 \\
\hline & & GDE2 cathode & 6.748 & 0.759 & 0.623 & 0.584 & - & - \\
\hline & & GDE2 anode & 6.466 & 0.620 & 0.278 & 0.220 & 0.224 & 0.262 \\
\hline & \multirow{5}{*}{$\mathrm{CPE}_{\mathrm{p}}-\mathrm{Q}\left(\mathrm{F} / \mathrm{cm}^{2}\right)$} & Reference & 0.042 & 0.038 & 0.042 & 0.046 & 0.050 & 0.055 \\
\hline & & GDE1 cathode & 0.063 & 0.049 & 0.053 & 0.064 & 0.086 & 0.088 \\
\hline & & GDE1 anode & 0.045 & 0.033 & 0.035 & 0.037 & 0.040 & 0.045 \\
\hline & & GDE2 cathode & 0.030 & 0.0189 & 0.084 & 0.037 & - & - \\
\hline & & GDE2 anode & 0.046 & 0.032 & 0.032 & 0.035 & 0.039 & 0.043 \\
\hline & \multirow{5}{*}{$\mathrm{CPE}_{\mathrm{p}}-\mathrm{n}$} & Reference & 0.850 & 0.850 & 0.850 & 0.850 & 0.850 & 0.850 \\
\hline & & GDE1 cathode & 0.800 & 0.850 & 0.850 & 0.850 & 0.850 & 0.850 \\
\hline & & GDE1 anode & 0.800 & 0.850 & 0.850 & 0.850 & 0.850 & 0.850 \\
\hline & & GDE2 cathode & 0.750 & 0.850 & 0.750 & 0.850 & - & - \\
\hline & & GDE2 anode & 0.800 & 0.850 & 0.850 & 0.850 & 0.850 & 0.850 \\
\hline & \multirow{5}{*}{$C_{\mathrm{p}}\left(\mathrm{F} / \mathrm{cm}^{2}\right)$} & Reference & 0.033 & 0.0196 & 0.0190 & 0.0199 & 0.0219 & 0.0253 \\
\hline & & GDE1 cathode & 0.048 & 0.028 & 0.028 & 0.033 & 0.045 & 0.045 \\
\hline & & GDE1 anode & 0.033 & 0.017 & 0.016 & 0.016 & 0.018 & 0.021 \\
\hline & & GDE2 cathode & 0.0176 & 0.009 & 0.031 & 0.019 & - & - \\
\hline & & GDE2 anode & 0.034 & 0.016 & 0.014 & 0.014 & 0.017 & 0.020 \\
\hline & \multirow{5}{*}{$f_{\mathrm{p}}(\mathrm{Hz})$} & Reference & 0.832 & 13.901 & 30.618 & 40.490 & 37.447 & 28.578 \\
\hline & & GDE1 cathode & 0.580 & 7.439 & 11.370 & 13.391 & 12.188 & 13.514 \\
\hline & & GDE1 anode & 0.772 & 15.236 & 33.191 & 42.838 & 35.531 & 25.123 \\
\hline & & GDE2 cathode & 1.341 & 23.459 & 8.133 & 14.625 & - & - \\
\hline \multirow{16}{*}{ Mass transfer circuit } & & GDE2 anode & 0.724 & 16.010 & 41.736 & 50.220 & 41.618 & 30.992 \\
\hline & \multirow{10}{*}{$\mathrm{CPE}_{\mathrm{d}}-\mathrm{Q}\left(\mathrm{F} / \mathrm{cm}^{2}\right)$} & Reference & - & - & - & 0.042 & 0.091 & 0.209 \\
\hline & & GDE1 cathode & - & - & - & 0.280 & 0.783 & 1.682 \\
\hline & & GDE1 anode & - & - & - & 0.060 & 0.142 & 0.368 \\
\hline & & GDE2 cathode & - & - & 0.178 & 1.891 & - & - \\
\hline & & GDE2 anode & - & - & 0.037 & 0.067 & 0.131 & 0.314 \\
\hline & & Reference & - & - & - & 0.912 & 0.412 & 0.187 \\
\hline & & GDE1 cathode & - & - & - & 0.124 & 0.069 & 0.051 \\
\hline & & GDE1 anode & - & - & - & 0.598 & 0.253 & 0.113 \\
\hline & & GDE2 cathode & - & - & 0.161 & 0.033 & - & - \\
\hline & & GDE2 anode & - & - & 0.945 & 0.523 & 0.276 & 0.129 \\
\hline & \multirow{5}{*}{$\mathrm{CPE}_{\mathrm{d}}-\mathrm{n}$} & Reference & - & - & - & 1.000 & 1.000 & 1.000 \\
\hline & & GDE1 cathode & - & - & - & 1.000 & 1.000 & 1.000 \\
\hline & & GDE1 anode & - & - & - & 1.000 & 1.000 & 1.000 \\
\hline & & GDE2 cathode & - & - & 1.000 & 1.000 & - & - \\
\hline & & GDE2 anode & - & - & 1.000 & 1.000 & 1.000 & 1.000 \\
\hline
\end{tabular}


TABLe 2: Continued.

\begin{tabular}{ccccccccc}
\hline Current density & Sample & OCV & $0.1\left(\mathrm{~A} / \mathrm{cm}^{2}\right)$ & $0.3\left(\mathrm{~A} / \mathrm{cm}^{2}\right)$ & $0.5\left(\mathrm{~A} / \mathrm{cm}^{2}\right)$ & $0.7\left(\mathrm{~A} / \mathrm{cm}^{2}\right)$ & $0.9\left(\mathrm{~A} / \mathrm{cm}^{2}\right)$ \\
\hline & Reference & - & - & - & 0.912 & 0.412 & 0.187 \\
& GDE1 cathode & - & - & - & 0.124 & 0.069 & 0.051 \\
$C_{\mathrm{d}}\left(\mathrm{F} / \mathrm{cm}^{2}\right)$ & GDE1 anode & - & - & - & 0.598 & 0.253 & 0.113 \\
& GDE2 cathode & - & - & 0.161 & 0.033 & - & - & 0.129 \\
& GDE2 anode & - & - & 0.945 & 0.523 & 0.276 & 4.068 \\
& Reference & - & - & - & 4.184 & 4.239 & 1.844 \\
& GDE1 cathode & - & - & - & 4.585 & 2.939 & 3.817 \\
& GDE1 anode & - & - & - & 4.400 & 4.425 & - \\
& \multirow{5}{*}{$(\mathrm{Hz})$} & GDE2 cathode & - & - & 5.535 & 2.575 & - & 3.934 \\
\hline
\end{tabular}

In the high CD region where two subcircuits are needed to fit experimental data, the relaxation frequencies are quite well separated to point out that two different physical phenomena are occurring, that is, charge and mass transfers; on average, the two phenomena are more clearly distinguishable when GDE1 or GDE2 are used as anodes than as cathodes.

\section{Discussion}

The spray-coated GDE1 performs quite well in the lowmedium CD range when it is used as an anode (Figures 4(a) and 4(c)), while it does not at the cathode side. The same trend is observed with GDE2, but in this case, the overall performances are somewhat lower.

Because the Pt load primarily affects the oxygen reduction reaction (ORR) occurring at the cathode, the somewhat lower amount of catalyst in GDE2 partly explains the poor performances of the assemblies tested with this GDE. However, the nominal Pt load and the Pt-particle size of the reference do not justify the worsening of the cell performances in the high $\mathrm{CD}$ region. Moreover, observing polarization curves at low flow rate (Figures 4(c) and 4(d)), it is clear that there are no flooding effects with the reference assembly and the curve drops to zero in correspondence of the limiting current $\left(1.1 \mathrm{~A} / \mathrm{cm}^{2}\right)$ as calculated by the stoichiometric ratio. On the contrary, GDE1 and GDE2 polarization curves drop to zero much earlier and this may be explained by flooding of the electrodes. Indeed, flooding occurs mainly at the cathode side in a PEMFC, due to the excess water produced by the ORR; so, if a GDM is inadequate to manage water, this becomes particularly evident when it is used on the cathode side, as pointed out by high mass transfer resistances from EIS analysis. In conclusion, the combined effect of lower Pt load and scarce ability in water management seems to explain the poor performances shown by Assembly 2. Comparison of $R_{\mathrm{d}}$ values (Tables 1 and 2) between Assembly 1 or 2 and Assembly Ref corroborates this hypothesis; there is a marked difference in $R_{\mathrm{d}}$ values when GDE1 is used as an anode and a cathode, and even in the best case, they are larger than the corresponding ones obtained in the reference assembly. The same considerations apply to GDE2, but in this case, the differences are even larger. Reducing the flow rate does worsen mass transport and causes an increase in the $R_{\mathrm{d}}$ values, even in the case of the reference, more pronounced than the corresponding increase in $R_{\mathrm{p}}$ values.

\section{Conclusions}

Two GDEs were obtained by spray coating; the surface morphology and the catalytic Pt-particle average size are comparable with commercial samples, and they do not seem to depend on the nature of the substrate or on some preparation procedures (e.g., nozzle dimension). The two GDEs have slightly different Pt-load: $0.5 \mathrm{mg} / \mathrm{cm}^{2}$ GDE1 and $0.4 \mathrm{mg} / \mathrm{cm}^{2}$ GDE2. The worst electrical performances of the GDEs prepared in this work compared to those of a commercial sample can be mainly ascribed to the poor water management. This phenomenon is highlighted by the equivalent circuit analysis of impedance spectra collected during the fuel cell operation. As the catalytic load and the average Pt particle size do not substantially differ from the reference sample, the bad water management behavior of the GDEs should be ascribed to the porous structure of the GDM. Indeed, higher mass transfer contributions and total internal resistance were found for both GDE1 and GDE2 compared to the reference sample; this behavior was more evident when lab-made GDEs were employed in the cathodic side, where water management issues are more pronounced. Such findings were possible due to the employment of electrochemical impedance spectroscopy, which is the most powerful tool to be used in fuel cells field to highlight and easily distinguish all the different physical phenomena, both kinetic and diffusive, taking place within the running device.

\section{Conflicts of Interest}

The authors declare that there is no conflict of interest regarding the publication of this paper.

\section{References}

[1] O. Erdinc and M. Uzunoglu, "Recent trends in PEM fuel cellpowered hybrid systems: investigation of application areas, 
design architectures and energy management approaches," Renewable and Sustainable Energy Reviews, vol. 14, no. 9, pp. 2874-2884, 2010.

[2] Y. Wang, K. S. Chen, J. Mishler, S. C. Cho, and X. C. Adroher, "A review of polymer electrolyte membrane fuel cells: technology, applications, and needs on fundamental research," Applied Energy, vol. 88, no. 4, pp. 981-1007, 2011.

[3] O. Groger, H. A. Gasteiger, and J. P. Suchsland, "Reviewelectromobility: batteries or fuel cells?," Journal of the Electrochemical Society, vol. 162, no. 14, pp. A2605-A2622, 2015.

[4] M. Zhou, H. L. Wang, and S. J. Guo, “Towards high-efficiency nanoelectrocatalysts for oxygen reduction through engineering advanced carbon nanomaterials," Chemical Society Reviews, vol. 45, no. 5, pp. 1273-1307, 2016.

[5] Y. M. Volfkovich, V. E. Sosenkin, and V. S. Bagotsky, "Structural and wetting properties of fuel cell components," Journal of Power Sources, vol. 195, no. 17, pp. 5429-5441, 2010.

[6] R. Othman, A. L. Dicks, and Z. Zhu, "Non precious metal catalysts for the PEM fuel cell cathode," International Journal of Hydrogen Energy, vol. 37, no. 1, pp. 357-372, 2012.

[7] Z. W. Chen, D. Higgins, A. P. Yu, L. Zhang, and J. J. Zhang, “A review on non-precious metal electrocatalysts for PEM fuel cells," Energy \& Environmental Science, vol. 4, no. 9, pp. 3167-3192, 2011.

[8] G. F. Alvarez, M. Mamlouk, S. M. Senthil Kumar, and K. Scott, "Preparation and characterisation of carbon-supported palladium nanoparticles for oxygen reduction in low temperature PEM fuel cells," Journal of Applied Electrochemistry, vol. 41, no. 8, pp. 925-937, 2011.

[9] S. Sui, X. Y. Wang, X. T. Zhou, Y. H. Su, S. Riffatc, and C. J. Liu, "A comprehensive review of Pt electrocatalysts for the oxygen reduction reaction: nanostructure, activity, mechanism and carbon support in PEM fuel cells," Journal of Materials Chemistry A, vol. 5, no. 5, pp. 1808-1825, 2017.

[10] G. Diloyan, M. Sobel, K. Das, and P. Hutapea, "Effect of mechanical vibration on platinum particle agglomeration and growth in polymer electrolyte membrane fuel cell catalyst layers," Journal of Power Sources, vol. 214, pp. 59-67, 2012.

[11] L. Cindrella, A. M. Kannan, J. F. Lin et al., "Gas diffusion layer for proton exchange membrane fuel cells-a review," Journal of Power Sources, vol. 194, no. 1, pp. 146-160, 2009.

[12] S. Park, J.-W. Lee, and B. N. Popov, "A review of gas diffusion layer in PEM fuel cells: materials and designs," International Journal of Hydrogen Energy, vol. 37, no. 7, pp. 5850-5865, 2012.

[13] B. Millington, V. Whipple, and B. G. Pollet, "A novel method for preparing proton exchange membrane fuel cell electrodes by the ultrasonic-spray technique," Journal of Power Sources, vol. 196, no. 20, pp. 8500-8508, 2011.

[14] C. Bois, A. Blayo, D. Chaussy, R. Vincent, A. G. Mercier, and C. Nayoze, "Catalyst layers for PEMFC manufactured by flexography printing process: performances and structure," Fuel Cells, vol. 12, no. 2, pp. 199-211, 2012.

[15] C. Ruengkit and N. Tantavichet, "Influence of gas diffusion layer on Pt catalyst prepared by electrodeposition for proton exchange membrane fuel cells," Thin Solid Films, vol. 636, pp. 116-126, 2017.

[16] H. B. Li, P. P. Yang, Z. Y. Xie, M. Sun, and Q. Z. Huang, "Selfsupported $\mathrm{N}$-doped carbon nanonet integrated on carbon paper for gas diffusion electrode," International Journal of Hydrogen Energy, vol. 42, no. 12, pp. 8216-8223, 2017.
[17] I. Gatto, A. Stassi, V. Baglio et al., "Optimization of perfluorosulphonic ionomer amount in gas diffusion electrodes for PEMFC operation under automotive conditions," Electrochimica Acta, vol. 165, pp. 450-455, 2015.

[18] H. Su, T. C. Jao, S. Pasupathi, B. J. Bladergroen, V. Linkov, and B. G. Pollet, "A novel dual catalyst layer structured gas diffusion electrode for enhanced performance of high temperature proton exchange membrane fuel cell," Journal of Power Sources, vol. 246, pp. 63-67, 2014.

[19] İ. Fırtına, S. Güner, and A. Albostan, "Preparation and characterization of membrane electrode assembly (MEA) for PEMFC," International Journal of Energy Research, vol. 35, no. 2, pp. 146-152, 2011.

[20] S. Latorrata, P. G. Stampino, E. Amici, R. Pelosato, C. Cristiani, and G. Dotelli, "Effect of rheology controller agent addition to micro-porous layers on PEMFC performances," Solid State Ionics, vol. 216, pp. 73-77, 2012.

[21] E. F. Diaz, C. Cuevas-Arteaga, N. Flores-Garcia, S. M. Sintillo, and O. Sotelo-Mazon, "Corrosion performance of AISI-309 exposed to molten salts $\mathrm{V}_{2} \mathrm{O}_{5}-\mathrm{Na}_{2} \mathrm{SO}_{4}$ at $700^{\circ} \mathrm{C}$ applying EIS and $\mathrm{R}_{\mathrm{p}}$ electrochemical techniques," Journal of Spectroscopy, vol. 2015, Article ID 826759, 12 pages, 2015.

[22] G. Bolat, D. Mareci, S. Iacoban, N. Cimpoesu, and C. Munteanu, "The estimation of corrosion behavior of NiTi and NiTiNb alloys using dynamic electrochemical impedance spectroscopy," Journal of Spectroscopy, vol. 2013, Article ID 714920, 7 pages, 2013.

[23] S. Godavarthi, J. Porcayo-Calderon, E. Vazquez-Velez, M. Casales-Diaz, D. M. Ortega-Toledo, and L. MartinezGomez, "Influence of the chemical composition in the electrochemical response of permanent magnets," Journal of Spectroscopy, vol. 2015, Article ID 356027, 16 pages, 2015.

[24] S. Sbrignadello, A. Tura, and P. Ravazzani, "Electroimpedance spectroscopy for the measurement of the dielectric properties of sodium chloride solutions at different glucose concentrations," Journal of Spectroscopy, vol. 2013, Article ID 571372, 6 pages, 2013.

[25] M. Ciureanu and R. Roberge, "Electrochemical impedance study of PEM fuel cells. Experimental diagnostics and modeling of air cathodes," Journal of Physical Chemistry B, vol. 105, no. 17, pp. 3531-3539, 2001.

[26] S. Latorrata, P. G. Stampino, C. Cristiani, and G. Dotelli, "Development of an optimal gas diffusion medium for polymer electrolyte membrane fuel cells and assessment of its degradation mechanisms," International Journal of Hydrogen Energy, vol. 40, no. 42, pp. 14596-14608, 2015.

[27] S. Latorrata, R. Balzarotti, P. G. Stampino, C. Cristiani, G. Dotelli, and M. Guilizzoni, "Design of properties and performances of innovative gas diffusion media for polymer electrolyte membrane fuel cells," Progress in Organic Coatings, vol. 78, pp. 517-525, 2015.

[28] S. Litster and G. McLean, "PEM fuel cell electrodes," Journal of Power Sources, vol. 130, no. 1-2, pp. 61-76, 2004.

[29] L. Omati, P. Gallo Stampino, G. Dotelli, D. Brivio, and P. Grassini, "Operative conditions effect on PEM-FC performance by in-situ and ex-situ analysis of gas diffusion media with different bulk textile structure," International Journal of Hydrogen Energy, vol. 36, no. 13, pp. 8053-8062, 2011.

[30] X.-Z. R. Yuan, C. Song, H. Wang, and J. Zhang, Electrochemical Impedance Spectroscopy in PEM Fuel Cells: Fundamentals and Applications, pp. 1-420, Springer, London, UK, 2010. 
[31] N. Wagner and E. Gülzow, "Change of electrochemical impedance spectra (EIS) with time during CO-poisoning of the Pt-anode in a membrane fuel cell," Journal of Power Sources, vol. 127, no. 1-2, pp. 341-347, 2004.

[32] R. Ferrero, G. Dotelli, P. Gallo Stampino, and S. Latorrata, "Discussion of critical measurement issues of impedance spectroscopy on PEM fuel cells," in IEEE International Workshop on Applied Measurements for Power Systems, AMPS, pp. 97-102, Aachen, Germany, 2012.

[33] S. Asghari, A. Mokmeli, and M. Samavati, "Study of PEM fuel cell performance by electrochemical impedance spectroscopy," International Journal of Hydrogen Energy, vol. 35, no. 17, pp. 9283-9290, 2010.

[34] P. G. Stampino, S. Latorrata, D. Molina, S. Turri, M. Levi, and G. Dotelli, "Investigation of hydrophobic treatments with perfluoropolyether derivatives of gas diffusion layers by electrochemical impedance spectroscopy in PEM-FC," Solid State Ionics, vol. 216, pp. 100-104, 2012.

[35] R. Ramasamy, E. Kumbur, M. Mench, W. Liu, D. Moore, and M. Murthy, "Investigation of macro- and micro-porous layer interaction in polymer electrolyte fuel cells," International Journal of Hydrogen Energy, vol. 33, no. 13, pp. 3351-3367, 2008.

[36] H. Kim and B. N. Popov, "Development of novel method for preparation of PEMFC electrodes," Electrochemical and Solid-State Letters, vol. 7, no. 4, pp. A71-A74, 2004.

[37] N. Wagner, "Characterization of membrane electrode assemblies in polymer electrolyte fuel cells using a.c. impedance spectroscopy," Journal of Applied Electrochemistry, vol. 32, no. 8, pp. 859-863, 2002.

[38] P. Gallo Stampino, L. Omati, C. Cristiani, and G. Dotelli, "Characterisation of nanocarbon-based gas diffusion media by electrochemical impedance spectroscopy," Fuel Cells, vol. 10, no. 2, pp. 270-277, 2010.

[39] J. Wu, X. Yuan, H. Wang, M. Blanco, J. Martin, and J. Zhang, "Diagnostic tools in PEM fuel cell research: part I electrochemical techniques," International Journal of Hydrogen Energy, vol. 33, no. 6, pp. 1735-1746, 2008.

[40] F. Alcaide, E. Brillas, and P.-L. Cabot, "EIS analysis of hydroperoxide ion generation in an uncatalyzed oxygen-diffusion cathode," Journal of Electroanalytical Chemistry, vol. 547, no. 1, pp. 61-73, 2003. 

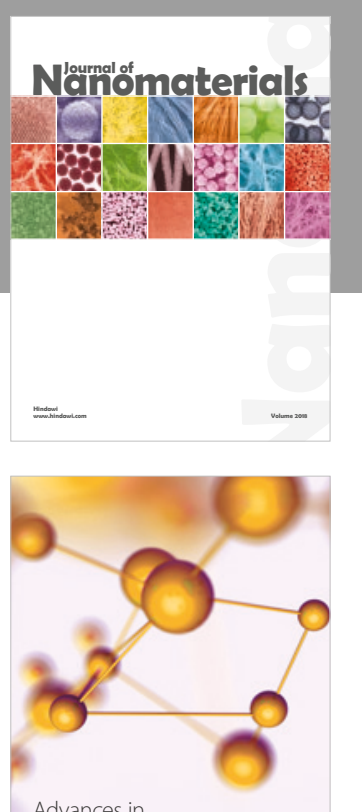

Physical Chemistry
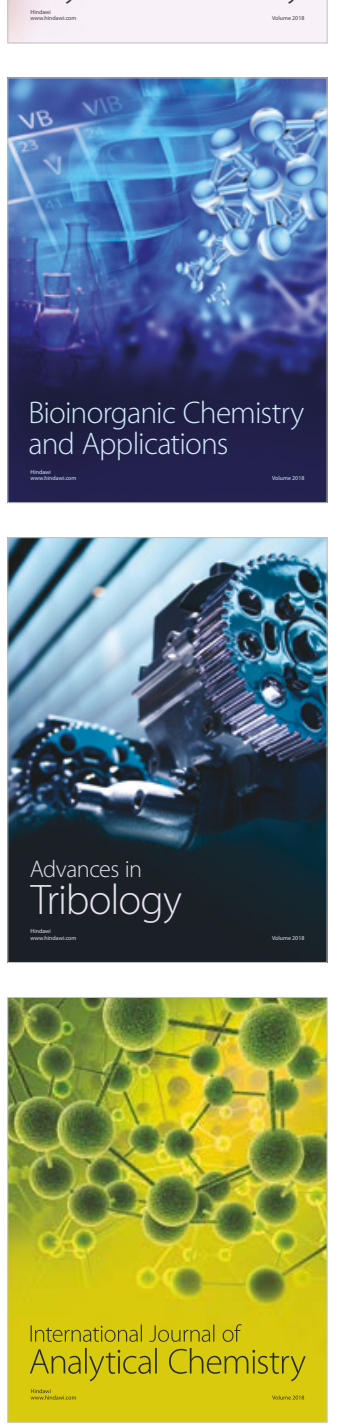

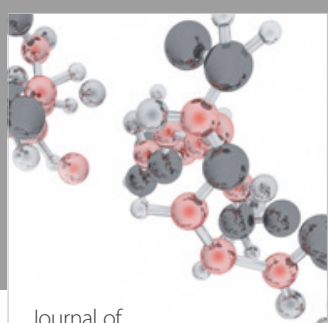

Analytical Methods

in Chemistry

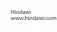

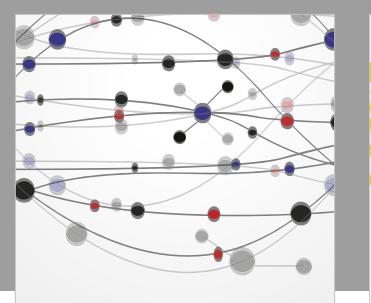

The Scientific World Journal

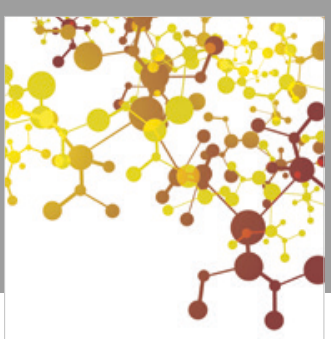

Journal of

Applied Chemistry
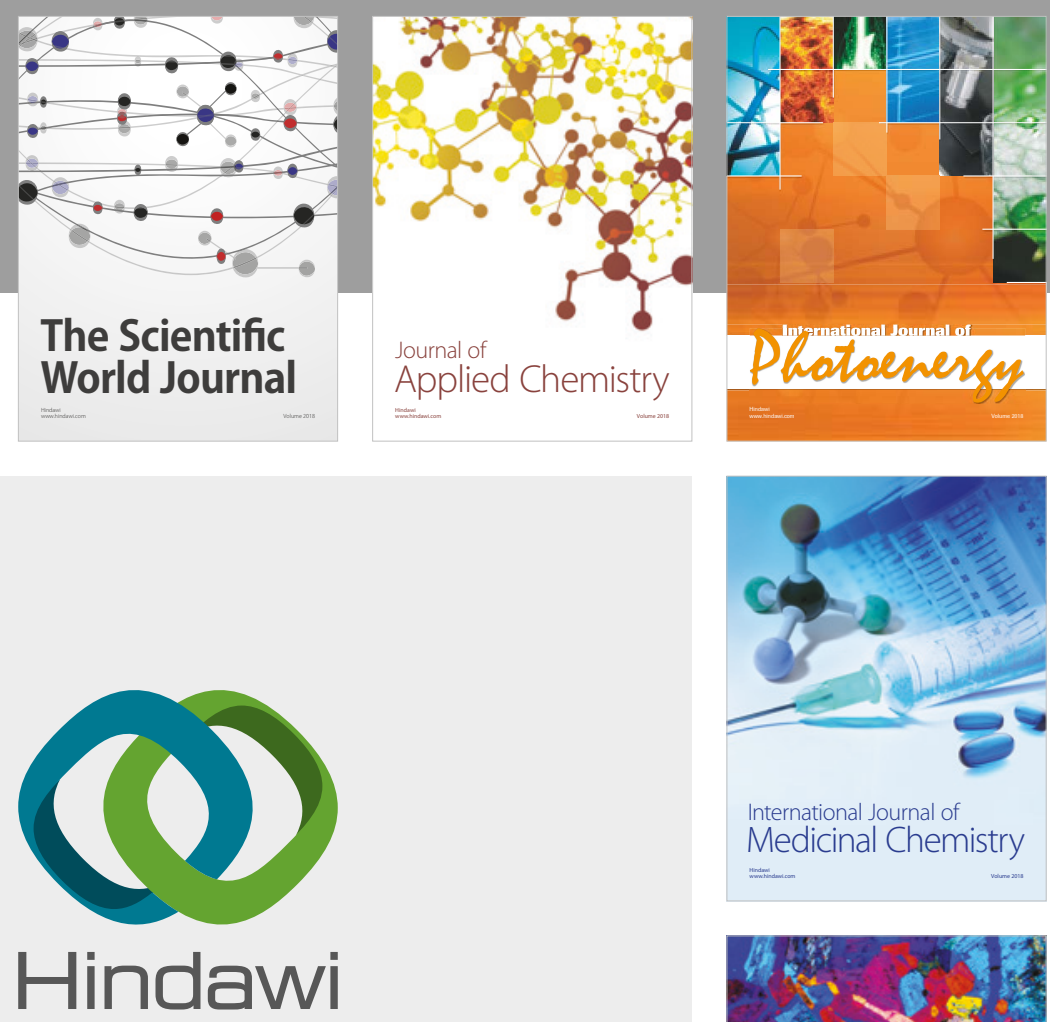

Submit your manuscripts at

www.hindawi.com
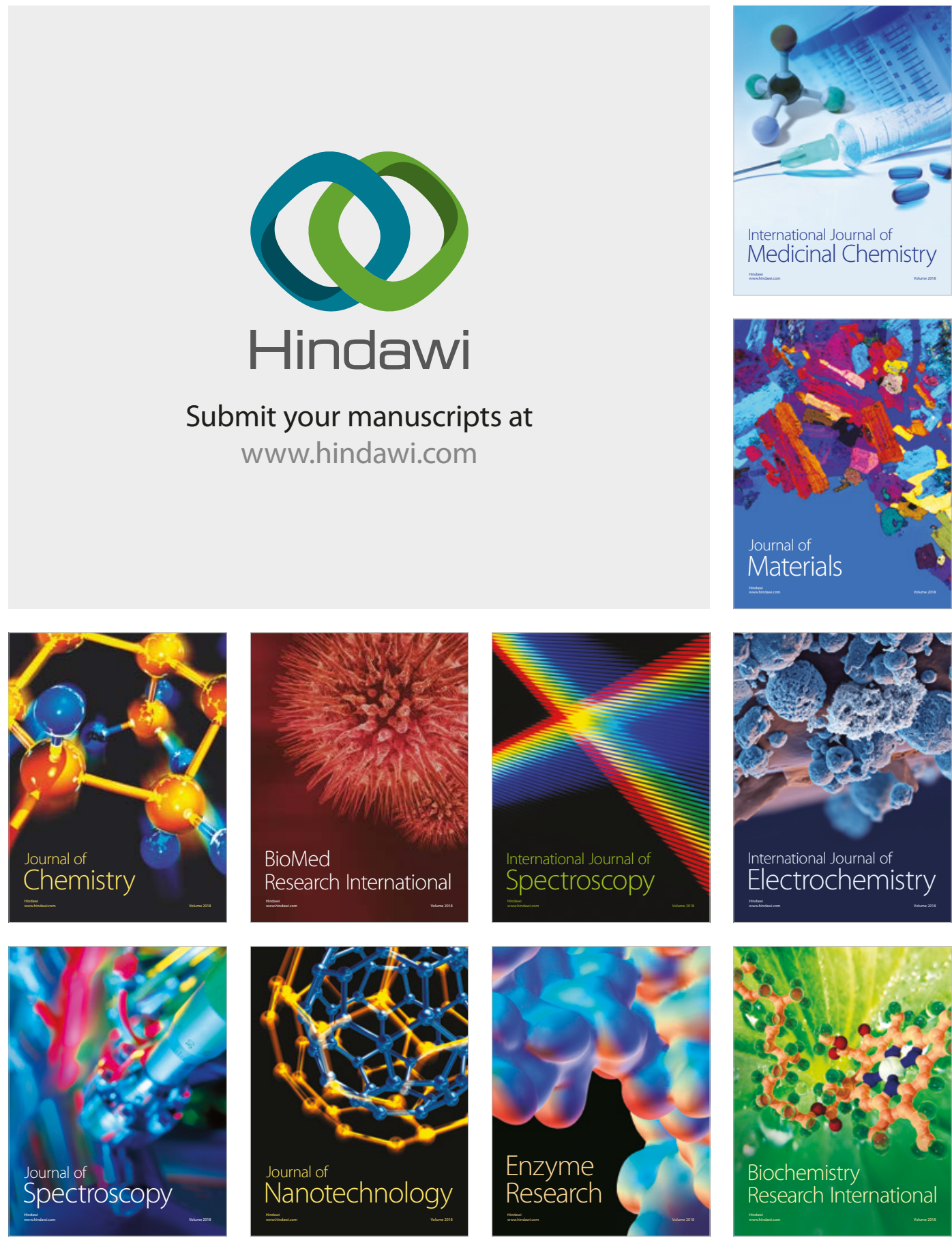
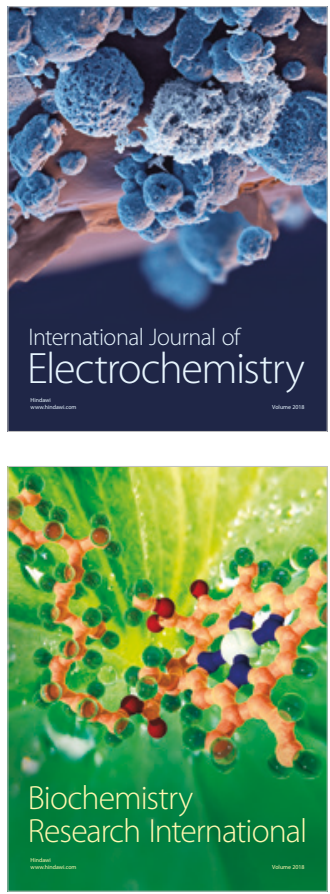